\title{
A Study on VMI-Based Supply-Chain System by Simulation Analysis
}

\author{
Shigeki Umeda \\ Musashi University \\ 1-26 Toyotama-kami Nerima Tokyo 176-8534 Japan \\ shigeki@cc.musashi.ac.jp
}

\begin{abstract}
This paper discusses performances of VMI-based supply-chain systems by using simulation. Two types of VMI system will be discussed in this paper: "Single-manager stock-driven model" and "Dual-managers scheduledriven model". Several scenarios would be introduced and tested by using typical example models.
\end{abstract}

Keywords: Supply-chain management, Business process engineering, Inventory Management, Vender-Managed Inventory, Simulation.

\section{Introduction}

A supply-chain is a network of autonomous and semi-autonomous business units collectively responsible for procurement, manufacturing, distribution activities associated with one or more families of products. Supply-chain system is, in a sense, a business system for the chain members to collaborate with each other by communication. Constructing of supply-chain is, as it were, a implementation of complex communication mechanisms among suppliers.

Evolutions of information and communication technologies such as internet have enabled frequent high-volume data changes in business communication. Internetbased environment, in particular, has provided low-cost data communication for all kinds of companies, including manufacturers, retailers, and distributors. Such communication environments have renovated inter/inner-enterprise communication mechanisms, and enabled information sharing of various types of data, such as products data, production management data, and demand trends data in market.

Vender Managed Inventory (VMI) system is currently one of the hottest topics in supply-chain management world. VMI systems utilize shared common demand data directly between downstream suppliers and upstream suppliers [1][2]. The upstream supplier (vendor) provides materials for its downstream supplier (customer) independently of customer's detail ordering. The vender continuously observes transitions of parts usage in customer's warehouses, and it independently decides volume and time of which it provides to customer. This system needs well-organized information sharing mechanisms between the vendor and the customer [3][4][5]. 
Another methodology is possible to implement VMI systems. This method is that a vendor periodically uses data how much parts the customer used. A Simple communications between vendors and a prime contractor can be also implemented by using information cards attached with inventory stocks. A well-known "Kanban" system is a typical example of this type [6]. A kanban card is a trigger of an inventory pullsignal from a downstream supplier to an up-stream supplier in a material-flow.

Based on the above discussions, the authors are developing a new simulationmodeling framework for VMI-based supply-chain systems. The models are based on a hybrid modeling approach, which combines discrete-event models representing processes in each business unit with system dynamics models representing external management environment such as marketing, transportations, and technological evolutions.

This paper, first, discusses VMI-based supply-chain systems. Second, two types of VMI models would be represented. The models include detail descriptions of business process activities. Third, the paper represents a modeling framework and implementations of simulation models. Finally, the paper discusses requirements specification to implement VMI-based supply-chain systems.

\section{Methodologies and Models}

\subsection{VMI (Vendor Managed Inventory) Methodologies}

There are many discussions of VMI system's implementation. These include from a simple re-order-point system to a complex system that shares data by using common databases. Meanwhile, there are very few discussions of VMI system models and their evaluation. VMI system is based on the concept of "consolidated inventories" between vendors and vendees. VMI uses various methods to realize minimum operational cost for inventory management and maximum reliance. Multilateral scheme is needed.

VMI system is essentially an inventory control system that vendors take initiative in delivery of goods. In usual business style, the vendors deliver materials according as received orders from vendees. Meanwhile, in VMI, the vendors deliver ones to vendees by their own decisions. The vendors and vendees must share demand data of final products in market by fully utilizing information network terminals.

We, first, consider a configuration of a simple supply-chain system to model information sharing mechanisms. This small system is composed of a "parts-supplier", "product-manufacturer", a set of consumers (market), a "product-manufacturer's manager", and a "parts-supplier's manager". The materials start parts-supplier, and arrives market by way of product-manufacturer. And, second, we discuss two types of modeling to utilize past demand data in market: "Single-manager Model", and "DualManagers Model".

\subsection{Single-Manager Model}

"Single-manager model" is a model that a part-supplier (Stock-driven supplier) gives orders to itself by using "Stock-driven" control method [6]. This supplier, located 
downstream in material-flow, uses two parameters to send materials to upstream: stock-replenishment level and stock-volume level. These two parameters of input material stock in down-stream are determined by the manufacturer's manager, which observes the changes of demands. Stock-driven supplier automatically replenishes material inventories based on these two parameters.

The supplier continuously observes stock volume at the "Product- manufacturer. It starts to produce products when stock volume is smaller than the stock-replenishment level, and it continues to work until the stock volume is equal to or greater than the stock-volume level. This stock-driven supplier generally works according to the following operational sequences.

(1) It periodically observes stock-volume data of a particular chain member.

(2) It starts producing when the stock volume goes down below the stockreplenishment level.

(3) It stops producing when the stock volume reaches the stock-volume level.

Product-manufacturer's manager predicts demands by using past demand data, and it also calculates Stock-driven data (Stock-volume level and Stock-replenish level) to set on. The details of activities of each member are as follows:

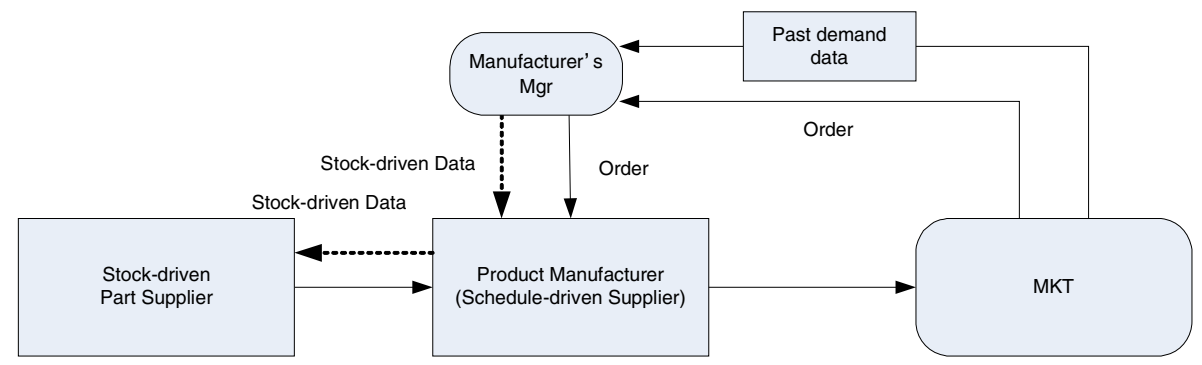

Fig. 1. Single Manager model

- Tasks of manufacturer's manager

(1) It receives orders from customers in Market.

(2) It gives orders to product manufacturer.

(3) It predicts demands by using past demand data.

(4) It calculates Stock-driven data (Stock-volume level and Stock-replenish level), and it set on these data.

- Tasks of product-manufacturer

(1) It receives production orders from Suppliers Manager.

(2) It withdraws parts and starts operations.

(3) It waits until parts arrival, if it does not have enough parts to start operations.

(4) It puts products for deliverer to carry them to customers in Market. 
- Tasks of stock-driven part supplier

(1) It periodically observes stock-replenish level.

(2) It starts to work to provide parts, when the part volume becomes smaller than Stock-replenishment level in product manufacturer.

(3) It finishes to work, when the part volume becomes larger than Stock-volume level in product manufacturer.

\subsection{Dual-Managers Model}

The model consists of a parts supplier and a product manufacturer. Both of these are schedule-driven suppliers, which work according as production orders from their own managers. These managers give production orders to their subordinates independently with each other. It is important that these managers use common dataset of past demands in market.

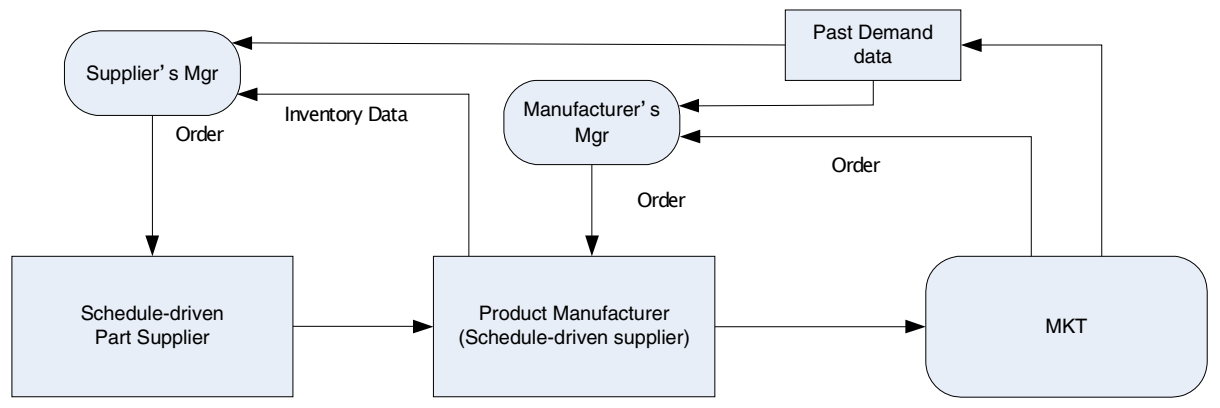

Fig. 2. Dual-Managers model

The details of activities of each member are as follows:

- Tasks of supplier's manager

(1) It receives orders from customers in Market

(2) It gives orders to product manufacturer

- Tasks of product manufacturer

(1) It receives production orders from Suppliers Manager

(2) It withdraws parts and starts operations

(3) It waits until parts arrival, if it does not have enough parts to start operations

(4) It puts products for deliverer to carry them to customers in Market

- Tasks of product manufacturer's manager

(1) It predicts demands by using both part inventory data at Product Manufacturer and the past demand data in market.

(2) It gives order to Schedule-driven part manufacturer

- Tasks of Schedule-driven part supplier

(1) It receives production orders from Vendors Manager

(2) It puts parts for deliverer to carry them to Product manufacturer 


\section{Simulation Experiments}

\subsection{Simulations Parameters}

Table.1 represents major run-parameters of simulation. "Replication" is a method to consider that single-run simulation often produces the result that is extremely different values from normal status by the effect of random numbers' seed. $\mathrm{N}(10,1)$ means, for an example, the normal distribution, which its mean is 10 lots and its variance (standard deviation) is 1 lot, respectively. In this method, the results of multiple runs with the different seeds are used to evaluate simulation results.

Table 1. Simulation parameters

\begin{tabular}{|l|l|}
\hline Items & Value \\
\hline Simulation duration & 100 days \\
\hline Replications & 5 times \\
\hline Demand volume distribution & $\mathrm{N}(10,1)$ or N $(10,3)$ \\
\hline $\begin{array}{l}\text { Interval of purchase-orders from Market to Manufacturer's } \\
\text { manager }\end{array}$ & 10 days \\
\hline $\begin{array}{l}\text { Interval of supply-orders from Supplier's manager to Part- } \\
\text { supplier }\end{array}$ & 10 days \\
\hline Interval of Manufacturing-orders to Manufacturer's manager & 10 days \\
\hline Initial volume of parts in Product-manufacturer & 50 lots \\
\hline Stock-replenishment volume & 1 day / lot \\
\hline Supplier lead-time & 1 day / lot \\
\hline Manufacturer lead-time & 50 lots \\
\hline Initial part-volume at Product-manufacturer & 0.5 days \\
\hline Transportation lead-time between suppliers & \\
\hline
\end{tabular}

\subsection{Simulation Results}

We used two types of simulation model previously described. Each model used two values of input parameter $\mathrm{s}$ that represent standards deviations. We cannot find large difference in major system performance indices, such as resource utilization, throughput, elapse time of entities, and inventory volume average. The difference has been shown in variance (standard deviation) of inventory volume data in product manufacturer.

The following four figures represent time-series changes of parts inventory volumes at product manufacturer. Fig. 3 and Fig. 4 show the case of stock-driven replenishment model, and Fig.5 and Fig.6 show the case of dual manager model. While the former shows obvious waved curves, the latter shows roughly straight-line. This result explains the reason why the variance of inventory in stock-driven model is larger than ones in dual manager model. 


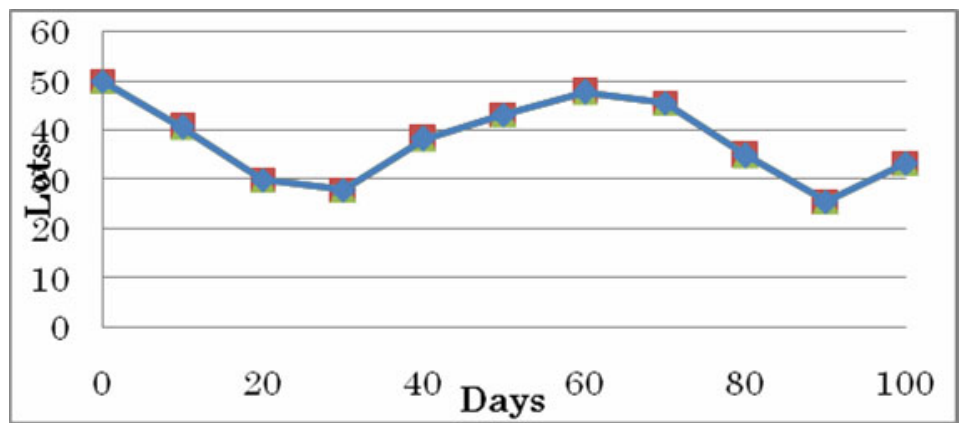

Fig. 3. Parts inventory volume at Product manufacturer in single-manager model simulation $($ Case: Demand distribution $=\mathrm{N}(10,1))$

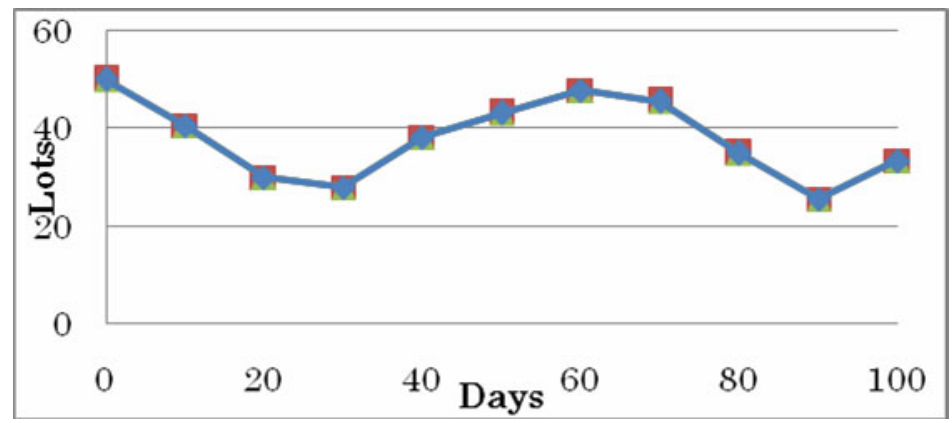

Fig. 4. Parts inventory volume at Product manufacturer in single-manager model simulation $($ Case: Demand distribution $=\mathrm{N}(10,3))$

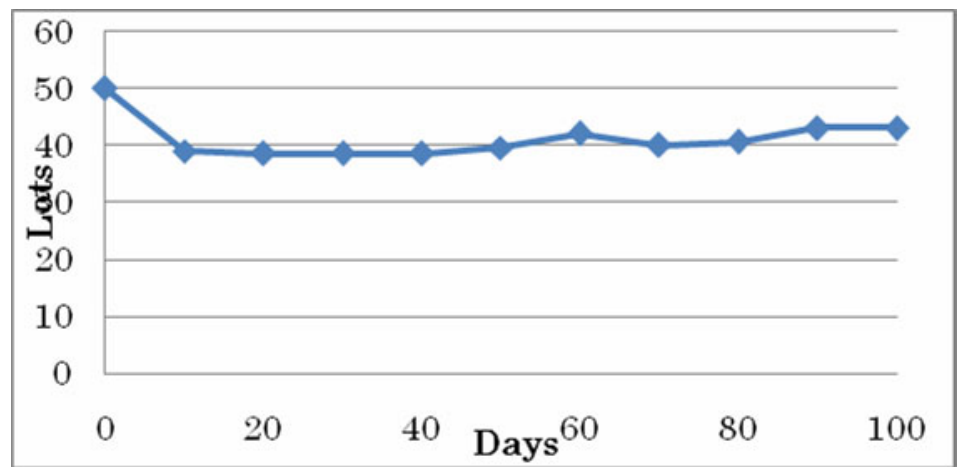

Fig. 5. Parts inventory volume at Product manufacturer in Dual-manager model simulation $($ Case: Demand distribution $=\mathrm{N}(10,1))$ 


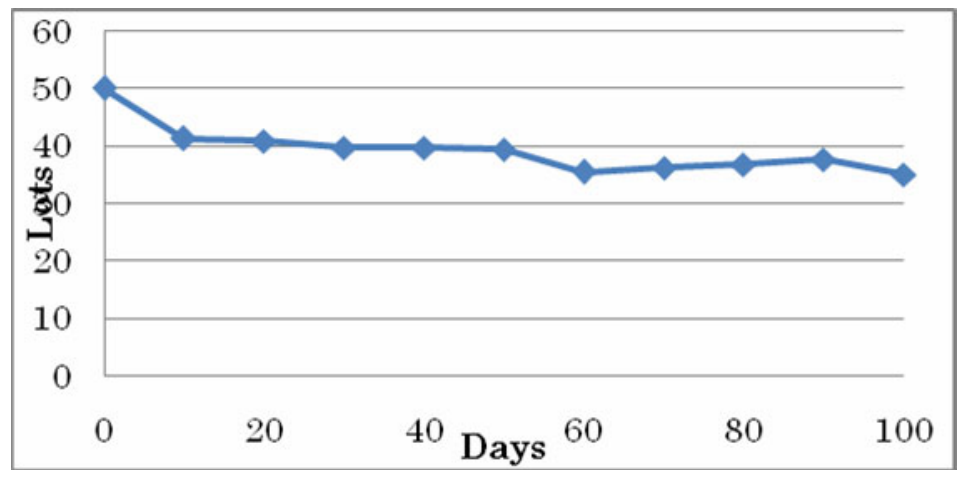

Fig. 6. Parts inventory volume at Product manufacturer in Dual-manager model simulation (Case: Demand distribution $=\mathrm{N}(10,3))$

\section{Consideration}

In single-manager model, up-stream supplier basically does nothing, while the parts volume in down-stream supplier is between "Stock-volume level" and "Stockreplenishment level". The vendor starts to supply parts to down-stream, when the inventory volume becomes lower than the predefined "Stock-replenishment level". Further, the up-stream continues to supply parts until the volume reaches "Stockvolume level", regardless of actual consumption of parts in the down-stream. The waved curves in Figure. 3 and 4 represent such shaker phenomena.

Meanwhile, in dual-manager model, two managers predict demand of down-stream by using common demand data. Accordingly, the supplier harmonizes with consumption of down-stream. Furthermore, the mean of demand volume is constant in this experiment. Accordingly, the supplier provides parts for it's down-stream manufacturer synchronizing with its consumption in respective of its variance of demand.

\section{Concluding Remarks}

Design and implementation of VMI (Vendor Managed Inventory) system are difficult tasks. Effective assessment methods are needed. This paper has discussed methodologies of VMI system, and it has proposed two types of simulation models: singlemanager model using a stock-driven replenishment method model and dual-manager model using common demand data. Characteristics of these models have been discussed through simulation experiments.

These two models stand for a difference in time-series data of part inventory volumes at the prime contractor. The mechanism of the dual-manager model denotes one of system advantages of VMI systems.

Communication mechanism proposed in this model still stays at a primitive stage to embody the whole feature of VMI systems. The detail design of communication model will be needed. Demand prediction logics, inventory management logics, and 
effects of supply-chain serviceability to market demand should be integrated in a monolith.

\section{References}

1. Kaipia, R., Holmstrom, J., Tanskanen, K.: VMI: What are you losing if you let your customer place orders? Production Planning and Control 13(1), 17-25 (2002)

2. Chenung, K.L., Lee, H.L.: The Inventory Benefit of Shipment Coordination and Stock Rebalancing in a Supply Chain. Management Science 48(2), 300-306 (2002)

3. Yao, Y., Dresner, M.: The inventory value of information sharing, continuous replenishment, and vendor-managed inventory. Transportation Research Part E 44, 361-378 (2008)

4. Luo, J.: Buyer-vendor inventory coordination with credit period incentives. Int. J. Production Economics 108, 143-152 (2007)

5. Achabal, D.D., Mcintyre, S.H., Smith, S.A., Kalyanam, K.: A Decision Support System for Vendor Managed Inventory. Journal of Retailing 76(4), 430-454 (2000)

6. Monden, Y.: Toyota Production System: An Integrated Approach to Just-In-Time, IIE (1998)

7. Umeda, S., Lee, T.: Integrated Supply Chain Simulation System - A Design Specification for a Generic Supply Chain Simulator, NISTIR 7146. National Institute of Standards and Technology (2004) 